Fisher. R. A., d Yates. F. Statistical table's for biological. agricultural and modical research. New York: Hafner. 1957.

GAïto. J. Unequal intervals and unequal $n$ in trend analysis. Psyehologicul Bulletin. 1965. 63. 125-127.

\section{GRADEM: A FORTRAN IV program for maintaining the student gradebook}

\author{
MARLENE D. ROTH and DAVID J. STANG \\ Queens College of the City Universing of New York \\ Flushing. New York 11367
}

Entering grades in a gradebook, calculating each student's average grade, and posting these grades for feedback to students can be an extremely tedious and time-consuming task. particularly in large classes or in classes with many grades on projects and quizzes. Errors are quite often made, and their correction is bothersome and time-consuming to both teacher and student. GRADEM is a program designed to facilitate the calculation and posting of students grades. The grades can be posted during the term to allow each student to see how well he is doing. Since the grades are recorded according to the students identification number. only the student and the professor need know the grades. Posting the grades in this manner also permits the student to determine his relative class standing. and provides incentive to improve his standing.
Lewis, D. Quanitative methods in psychology. New York: Mc Graw-Hili. 1960$)$.

Stang. D. J., \& O'Connell, E. J. TREND: A FORTRAN IV subroutine for trend analysis, Behavioral Science. 1973. 18. 77.

Input. For each test: (1) a title card which contains the number of students who have taken that test. the number of questions on that test. and the name of the test: (2) one card for each student who took the test. containing the student's identitication number and test grade.

Output. (1) Class and other identification; (2) test titles and descriptions: (3) the sum (or average) of the students grades in descending order with each student's test marks and identification number.

Computer and language. This program was written on the Xerox Sigma 7 . and will run on any Xerox computer. With some slight alterations to the code. this program will run on any computer that supports FORTRAN. The maximum core requirement is $5 K$, and the total job time is well under $1 \mathrm{~min}$.

Restrictions. The maximum number of students allowed is 200 . and the nuximum number of tests is 15 (although both can be expanded, if needed, by minimal alteration of the code). If the latter alteration is made, the format of the output must also be changed to allow for the printing of the identitication number. the test grades. and the sum (or average) of the grades on one line.

Availability. A copy of the listing. documentation. and sample output can be obtained free of charge by writing David Stang. Department of Psychology, Queens College of the City University of New York, Flushing. New York 11367. 